\title{
High BMI among adult haemodialysis patients at a UK hospital: an indicator of poor or adequate nutritional status?
}

\author{
N.A Gityamwi ${ }^{1}$, M.A Hellyer ${ }^{2}$, K.H. Hart ${ }^{1}$ and B Engel ${ }^{1}$ \\ ${ }^{1}$ School of Biosciences and Medicine, University of Surrey, Guildford, GU2 $7 X H$ and ${ }^{2}$ Department of Nutrition and \\ Dietetics, Queen Alexandra Hospital, Portsmouth, PO6 3LY
}

In the general population obesity is associated with increased risk of morbidity and mortality. In contrast, studies indicate better survival among overweight/obese HD patients ${ }^{1,2}$. However, it should not be forgotten that obesity (excess weight) does not necessarily imply good nutritional status as muscle wasting can occur, concealed by fat accumulation, a condition called "sarcopenic obesity" $(\mathrm{SO})^{3}$. SO has several metabolic implications including inflammation ${ }^{4}$ and increased risk of cardiovascular events ${ }^{5}$ which are also known to be the leading causes of mortality in chronic kidney disease (CKD) patients. This study aimed to audit the nutritional status and biochemical parameters of UK haemodialysis (HD) patients and to compare these parameters between dialysis settings.

Current patients who had been receiving treatment for at least 6 months at one hospital (via home or satellite unit HD) were eligible for inclusion. Parameters under observation were BMI, serum albumin (Alb), CRP, Adjusted Calcium, Phosphate, iPTH, Urea, Creatinine, Haemoglobin and Ferritin levels with data extracted retrospectively from patient records. Data were analysed using SPSS version 22 and for each biochemical parameter the proportion of patients achieving, exceeding or below the K/DOQI (2006) reference range standards was calculated.

One hundred and forty seven patients were included in the audit (46 receiving home and 101 satellite HD). BMI, Alb and CRP levels raised concern in the sample as a whole (see Table). Only Alb was significantly associated with HD setting with status being better in home HD patients (BMI: $X^{2}=3 \cdot 33, p=0 \cdot 18$; Alb: $X^{2}=3 \cdot 68, p=0 \cdot 03$; CRP: $X^{2}=0 \cdot 57, p=0 \cdot 45$ ).

\begin{tabular}{|c|c|c|c|c|c|c|}
\hline \multirow[b]{2}{*}{ STATUS } & \multicolumn{3}{|l|}{ HOME } & \multicolumn{3}{|c|}{ SATELLITE } \\
\hline & $\begin{array}{l}\text { BMI } \\
(n=41) \\
\%(n)\end{array}$ & $\begin{array}{l}\text { ALBUMIN } \\
(\mathrm{n}=45) \\
\%(\mathrm{n})\end{array}$ & $\begin{array}{l}\text { CRP } \\
(n=44) \\
\%(n)\end{array}$ & $\begin{array}{l}\text { BMI } \\
(n=99) \\
\%(n)\end{array}$ & $\begin{array}{l}\text { ALBUMIN } \\
(\mathrm{n}=98) \\
\%(\mathrm{n})\end{array}$ & $\begin{array}{l}\text { CRP } \\
(n=95) \\
\%(n)\end{array}$ \\
\hline Below normal range & $0 \cdot 0(0)$ & $88 \cdot 9(40)$ & $0 \cdot 0(0)$ & $3 \cdot 0(3)$ & $98 \cdot 0(96)$ & $0 \cdot 0(0)$ \\
\hline Within normal range & $26 \cdot 8(11)$ & $11 \cdot 1(5)$ & $38 \cdot 6(17)$ & $35 \cdot 4(35)$ & $2 \cdot 0(2)$ & $30 \cdot 5(29)$ \\
\hline Above normal range & $73 \cdot 2(30)$ & $0 \cdot 0(0)$ & $61.4(27)$ & $61.6(61)$ & $0.0(0)$ & $69 \cdot 5(66)$ \\
\hline
\end{tabular}

The majority of patients had a BMI above the healthy range (overweight or obese $\left(>25 \mathrm{~kg} / \mathrm{m}^{2} \mathrm{BMI}\right)$ ). High CRP ( $\left.>5 \mathrm{mg} / \mathrm{l}\right)$ and low albumin levels $(<40 \mathrm{~g} / \mathrm{l})$ were also observed in the majority of the sample.

Although high BMI as a marker of good nutritional status has been positively associated with improved survival in HD patients ${ }^{1,2}$ an increased CRP and decreased albumin indicate an inflammatory state and have been associated with loss of lean muscle mass and increased cardiovascular mortality (defined as the 'malnutrition, inflammation syndrome' $)^{2,3,4,6}$. This raises concern as to whether the BMI levels observed in this sample of HD patients indicate better nutrition or increased health risk and whether there is indeed no significant difference in nutritional status between the two settings regardless of differences in albumin status. Further research to investigate this via appropriate measures for muscle mass, strength and physical performance are required ${ }^{6}$ to ascertain the impact of the inflammatory state on body composition and nutritional status of these patients in order to inform appropriate nutritional intervention.

1. Glanton CW, Hypolite IO, Hshieh PB et al. (2003) Ann Epidemiol, 13(2), 136-143.

2. Kalantar-Zadeh K, Kopple JD, Kilpatrick RD et al. (2005) Am J Kidney Dis, 46(3), 489500

3. Honda H, Qureshi AR, Axelsson J et al. (2007) Am J Clin Nutr, 86(3), 633-638.

4. Witasp A, Carrero JJ, Heimburger O et al. (2011) J Intern Med, 269(4), 410-419.

5. Kamimura MA, Carrero JJ, Canziani ME et al. (2013) Nutr Metab Cardiovasc Dis, 23(9), 891-897.

6. Reijnierse EM, Trappenburg MC, Leter MJ et al. (2015) PLoS ONE, 10(8), e0135933. 